\title{
Analisis Thermal pada Pembangkit Listrik Tenaga Panas Bumi PT. Indonesia Power UPJP Kamojang
}

\author{
Kadek Chestha Amrita, Gunawan Nugroho \\ Departemen Teknik Fisika, Fakultas Teknologi Industri \\ Institut Teknologi Sepuluh Nopember (ITS) 60111 Indonesia \\ e-mail: gunawan@ep.its.ac.id
}

\begin{abstract}
Abstrak-Pada saat ini PT. Indonesia Power UPJP Kamojang mengoperasikan PLTP dengan kapasitas total sebesar $375 \mathrm{MW}$, untuk penelitian Studi berikut menggunakan unit II pada PLTP Kamojang. Agar memperoleh kapasitas listrik yang optimum maka diperlukan efisiensi yang baik dari proses produksi dengan menganalisa efisiensi thermal dan eksergi serta menghitung biaya kerugian eksergi berdasarkan termoekonomi. Berdasarkan perhitungan yang telah dilakukan, maka didapatkan efisiensi thermal sistem sebesar $19,41 \%$. Dengan eksergi loss terbesar dan terendah pada komponen turbin dan cooling tower sehingga biaya rugi eksergi pada cooling tower bernilai kecil sebesar $7.394 .034,76 \mathrm{Rp} / \mathrm{bln}$ dan biaya rugi eksergi pada turbin sebesar $252.766 .682,24 \mathrm{Rp} / \mathrm{bln}$, untuk nilai efisiensi eksergi yang terbesar pada komponen separator yaitu $\mathbf{9 9 , 4 7 \%}$ sedangkan efisiensi eksergi sistemnya sebesar $47,06 \%$. Dari hasil tersebut dapat diketahui bahwa efisiensi sistem dipengaruhi oleh performansi masing-masing komponen, dan banyaknya eksergi yang hilang dalam komponen-komponen tersebut. Sedangkan saran yang bisa dilakukan untuk pembangkit listrik yang telah diteliti adalah perlu dilakukannya maintenance secara rutin terhadap komponen turbin serta kondensor dikarenakan memiliki eksergi loss yang cukup tinggi yang akan mempengaruhi efisiensi dari sistem.
\end{abstract}

Kata Kunci-PLTP Kamojang, Eksergi, Biaya Rugi Eksergi.

\section{PENDAHULUAN}

$\mathrm{B}$ eberapa tahun belakangan ini, krisis energi yang terjadi di Indonesia menjadi perbincangan. Berdasarkan data dari Handbook of Energy \& Economic Statistics of Indonesia tahun 2010, sektor industri mengonsumsi energi terbesar yaitu sekitar 40,86\% dari total konsumsi energi di tahun 2009. Sedangkan di tahun 2009, sektor industri mengonsumsi energi sebesar $38,47 \%$ yang berasal dari sektor gas sehingga efisiensi energi menjadi hal yang sangat penting dan berpengaruh. Blueprint Pengelolaan Energi Nasional tahun 2006 memiliki data yang menyatakan bahwa elastisitas energi di Indonesia sebesar 1,84 di mana angka ini jauh lebih tinggi dibanding negara - negara maju lainnya sehingga Indonesia dikatakan negara yang tidak efisien dalam memanfaatkan energi[1].

Permasalahan terkait energi semakin kompleks, terutama dalam hal pemenuhan akan kebutuhan energi listrik. Konsumsi energi listrik semakin bertambah dengan meningkatnya jumlah populasi manusia tiap tahunnya. Selama ini kebutuhan energi listrik masih mengandalkan penggunaan energi tak terbarukan seperti minyak bumi, batu bara, dan gas alam, dimana persediaannya di alam kian menipis. Energi terbarukan merupakan salah satu solusi tepat untuk mengatasi permasalah di atas. Panas bumi sebagai salah satu energi terbarukan, saat ini banyak dimanfaatkan sebagai pembangkit listrik di beberapa negara termasuk Indonesia. Pembangit Listrik Tenaga Panas Bumi (Geothermal) memiliki potensi yang besar untuk dikembangkan di beberapa daerah Indonesia karena secara geologis terletak di antara pertemuan tiga lempeng tektonik utama yaitu Lempeng Eropa-Asia, India-Australia, dan Pasifik. Sehingga berperan dalam pembentukan gunung berapi yang membuat sekitar $40 \%$ potensi panas bumi dunia terdapat di Indonesia. Dengan potensi pembangkitan sebesar 28.100 MW tersebut, disayangkan bahwa pemanfaatan PLTP di Indonesia masih sangatlah kecil yaitu sekitar 1.197 MW atau 4\% dari total potensi yang ada[2]. Pada prinsipnya cara kerja pembangkit listrik tenaga panas bumi adalah sama dengan pembangkit listrik tenaga uap, kecuali pada asal steam. Pada PLTP steam diperoleh dari reservoir dengan memanfaatkan panas bumi, sedangkan pada pembangkit tenaga uap steam diperoleh dari proses boiler[3]. Dengan demikian kualitas fisik steam yang dihasilkan berbeda pula.

Pada saat ini PT. Indonesia Power UPJP Kamojang mengoperasikan PLTP dengan kapasitas total sebesar 375 MW, yaitu: unit PLTP Kamojang, unit PLTP Darajat, unit PLTP Gunung Salak, dan unit PLTP Ulumbu. Agar memperoleh kapasitas listrik yang optimum maka diperlukan efisiensi yang baik dari proses produksi dengan memperhatikan performansi masing-masing unit. Perubahan keluaran daya listrik sebuah pembangkit listrik tenaga panas bumi berkaitan dengan kondisi steam dari sumur produksi. Konsistensi produksi daya listrik menyebabkan keuntungan dari perusahaan pun akan tetap. Sebaliknya penurunan daya listrik dapat menimbulkan kerugian, sehingga harus diantisipasi. Dengan demikian, analisa efisiensi thermal berdasarkan hukum termodinamika digunakan untuk menganalisa system thermal dari pembangkit listrik tenaga panas bumi PT. Indonesia Power UPJP Kamojang. Selain itu, digunakan analisa eksergi dengan melakukan identifikasi aliran eksergi, menentukan lokasi dimana besarnya kerugian eksergi yang terjadi serta menghitung biaya kerugian eksergi berdasarkan termoekonomi. Oleh karena itu, penelitian ini dilakukan untuk mengidentifikasi lokasi di mana eksergi terbuang atau hilang yang bisa mengurangi performansi dari efisiensi sistem yang disebabkan oleh peralatan atau komponen-komponen pembangkit listrik tenaga panas bumi PT. Indonesia Power UPJP Kamojang.

\section{METODOLOGI}

Metodologi penelitian adalah kerangka dasar dari tahapan penyelesaian studi. Metodologi tersebut mencakup semua kegiatan yang akan dilakukan untuk memecahkan masalah 
atau melakukan proses analisa terhadap permasalahan pada studi ini.
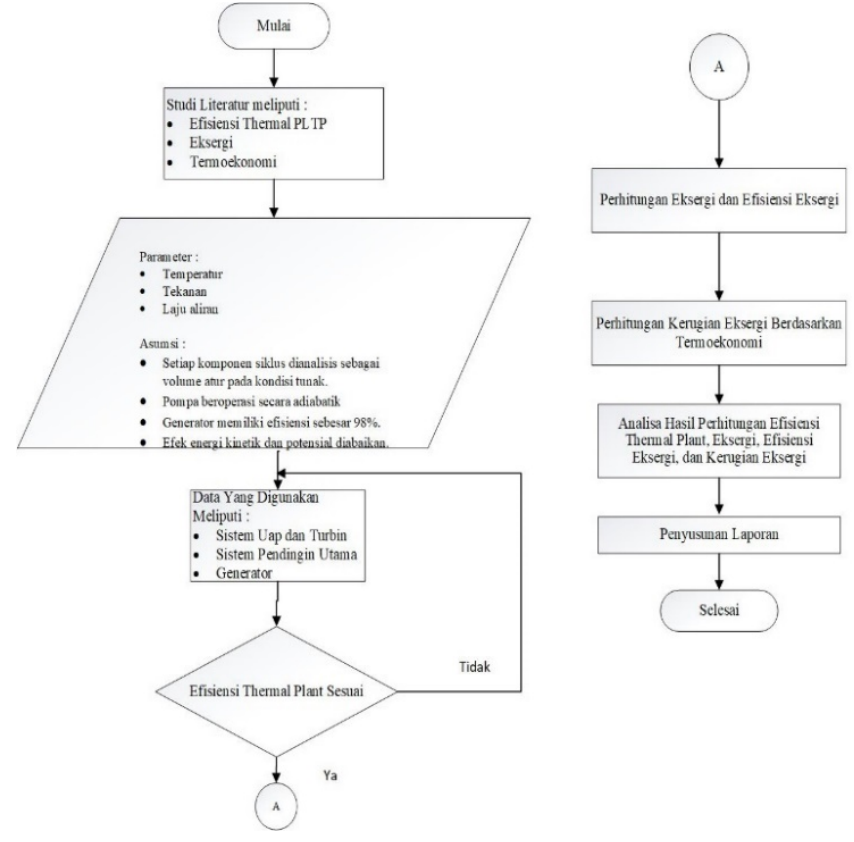

\section{A. Studi Literatur}

Pelaksanaan studi ini diawali dengan melakukan studi literatur. Studi literatur bertujuan untuk meningkatkan pemahaman peneliti terhadap topik penelitian yang akan diambil. Studi literatur dilakukan dengan mempelajari pengetahuan pendukung seperti efisiensi thermal PLTP, eksergi, dan lain-lain. Studi literatur dilakukan dengan mengumpulkan beberapa bahan referensi berupa jurnal ilmiah terkait perkembangan penelitian yang telah dilaksanakan sebelumnya.

\section{B. Parameter dan Asumsi}

Pada proses menyelesaikan penelitian ini, ada baiknya untuk menentukan parameter dan asumsi yang digunakan untuk mempermudah dalam penyelesaian permasalahan. Parameter yang terkait pada penelitian ini adalah tekanan, temperatur, dan laju aliran. Selain itu, asumsi yang digunakan pada penelitian ini adalah setiap komponen pada siklus dianalisis sebagai volume atur pada kondisi tunak, pompa beroperasi secara adiabatik, energi kinetik dan potensial diabaikan, dan lain-lain.

\section{Data yang digunakan}

Penelitian ini menggunakan data pada saat plant sedang beroperasi di PLTP UPJP Kamojang PT. Indonesia Power. Data yang digunakan meliputi data operasi yaitu sistem uap dan turbin, sistem pendingin utama dan generator pada Unit II di PLTP Kamojang. Selain data operasi yang digunakan, terdapat data teknik dengan nomor series TD-01 dan TD-02.

\section{Perhitungan Efisiensi Thermal Plant}

Pada penelitian ini untuk menghitung efisiensi thermal pembangkit listrik tenaga panas bumi UPJP kamojang PT. Indonesia Power digunakan tahapan-tahapan perhitungan. Berikut ini adalah tahapan untuk menghitung efisiensi thermal pada pembangkit listrik tenaga panas bumi Kamojang :

1. Mencari nilai entalpi (h3) dan entropi (s3) pada tekanan uap masuk turbin (P1) dengan menggunakan (Table A-6 Properties of Superheated Water Vapor).
2. Mencari nilai entalpi fluida (hf), entalpi uap (hg), dan entalpi campuran (hfg) pada tekanan keluar turbin (P2) dengan menggunakan (Table A-5 Properties of Saturated Water (Liquid - Vapor): Pressure Table).

3. Mencari nilai entropi fluida (sf), entropi uap (sg), dan entropi campuran (sfg) pada tekanan keluar turbin (P2) dengan menggunakan (Table A-5 Properties of Saturated Water (Liquid - Vapor): Pressure Table).

4. Menghitung entalpi keluaran uap dari turbin (h4) dengan persamaan :

$$
(\mathrm{h} 3-\mathrm{h} 4) . \dot{\mathrm{m}}=\frac{\text { daya generator }(\mathrm{MW})}{\text { efisiensi generator }}
$$

5. Menghitung fraksi uap(x) turbin dengan persamaan :

$$
\mathrm{s} 4 \mathrm{~s}=\mathrm{s} 3=\mathrm{sf} 4+\mathrm{x} . \mathrm{sfg} 4
$$

dengan asumsi bahwa entropi masukan pada turbin(s3) bernilai sama dengan entropi $\left(\mathrm{s} 4_{\mathrm{s}}\right)$ keluaran dari turbin yaitu $6.81 \mathrm{~kJ} / \mathrm{kg} . \mathrm{K}$

6. Menghitung entalpi keluaran turbin (h4s) dengan persamaan :

$$
\mathrm{h} 4 \mathrm{~s}=\mathrm{hf} 4+\mathrm{x} . \mathrm{hfg} 4
$$

7. Menghitung efisiensi dari turbin dengan persamaan :

$$
\eta t=\frac{W}{W_{s}}=\frac{h 3-h 4}{h 3-h 4_{s}}
$$

8. Menghitung jumlah energi yang dibuang oleh kondensor dengan persamaan berikut :

$$
q_{\text {kondensor }}=h_{5}-h_{4}
$$

dan untuk menghitung kinerja kondensor adalah sebagai berikut :

$$
Q_{\text {kondensor }}=\dot{\mathrm{m}} \cdot q_{\text {kondensor }}
$$

9. Menghitung kerja pompa

$$
-w=v \cdot\left(p_{2}-p_{1}\right)
$$

10. Menghitung laju perpindahan kalor dari sumber energi ke dalam fluida kerja yang melalui receiving header dengan persamaan :

$$
q_{\text {boiler }}=\mathrm{h} 3-\mathrm{h} 6
$$

maka energi pada receiving header adalah sebagai berikut:

$$
Q_{\text {boiler }}=\dot{\mathrm{m}} \cdot q_{\text {boiler }}
$$

Jadi untuk menghitung total efisiensi thermal plant menggunakan persamaan berikut[4]:

$$
\eta \text { sistem }=\frac{\sum W}{\text { Qin }}=\frac{W_{\text {turbin }}-W_{\text {total pompa }}}{h 3-h 6}
$$

\section{E. Perhitungan Eksergi dan Efisiensi Eksergi}

Setelah menghitung efisiensi thermal pembangkit listrik tenaga panas bumi yang ada di PT. Indonesia Power UPJP Kamojang, dilanjutkan menghitung eksergi dan efisiensi eksergi dari pembangkit listrik tenaga panas bumi tersebut dengan persamaan-persamaan berikut[1]:

$$
E_{k}=m\left[\left(h_{k}-h_{0}\right)-T_{0}\left(S_{k}-S_{0}\right)\right]
$$

Dimana : $E_{k}=$ eksergi pada state $\mathrm{k}(\mathrm{kW})$

$h_{k}=$ entalpi pada state $(\mathrm{kJ} / \mathrm{kg})$

$h_{0}=$ entalpi pada temperatur lingkungan $(\mathrm{kJ} / \mathrm{kg})$

$S_{k}^{o}=$ entropi spesifik pada state $\mathrm{k}(\mathrm{kJ} / \mathrm{kg} . \mathrm{K})$

$S_{0}^{o} \quad=$ entropi spesifik udara pada temperatur lingkungan (kJ/kg.K)

$T_{0} \quad=$ temperatur lingkungan $\left({ }^{\circ} \mathrm{C}\right)$

Sebelum menghitung efisiensi eksergi dari setiap unit/komponen, maka dihitung juga eksergi loss pada setiap unit dengan persamaan sebagai berikut[5]:

$$
E_{\text {kloss }}=E_{\text {kinput }}-E_{\text {koutput }}
$$


Dengan demikian, dapat dihitung efisiensi eksergi dari setiap unit yang membandingkan antara eksergi masuk sebagai eksergi yang digunakan dengan eksergi keluar sebagai eksergi yang termanfaatkan dengan persamaan berikut ini[5]:

$$
\eta_{\text {ex }}=\frac{E_{\text {out }}}{E_{\text {in }}}
$$

Selain itu, dihitung juga efisiensi eksergi overall dari pembangkit listrik tenaga panas bumi PT. Indonesia Power UPJP Kamojang dengan persamaan berikut[5]:

$$
\eta_{I I}=\frac{W_{\text {net }}}{E_{\text {in }}}
$$

Dimana :

$\eta_{\text {II }} \quad=$ efisiensi eksergi

$\dot{\mathrm{W}}_{\text {net }}=$ daya listrik netto

Ěin = eksergi total yang masuk ke plant.

\section{F. Perhitungan Kerugian Eksergi Berdasarkan Termoekonomi}

Perhitungan biaya kerugian eksergi dari pembangkit listrik tenaga panas bumi PT. Indonesia Power UPJP Kamojang dengan menggunakan acuan pada Tarif Dasar Listrik (TDL) per kWh. Tarif Dasar Listrik di Indonesia per bulan Maret 2018 untuk golongan I-4/TT dengan batas daya lebih dari $30.000 \mathrm{kVa}$ adalah sebesar 1.467,28 Rp/kWh, sehingga persamaan berikut yang digunakan untuk menghitung biaya kerugian eksergi pada PLTP Kamojang[6]:

$$
C=E x T D L \times \text { hours }
$$

Dimana :

$$
\begin{array}{ll}
C & =\text { biaya rugi eksergi }(\mathrm{Rp} / \mathrm{bln}) \\
E & =\text { Eksergi loss }(\mathrm{kW}) \\
T D L & =\text { Tarif Dasar Listrik }(\mathrm{Rp} / \mathrm{kWh}) \\
\text { hours } & =\text { waktu operasi }
\end{array}
$$

\section{HASIL DAN PEMBAHASAN}

\section{A. Asumsi}

Asumsi yang digunakan untuk mempermudah dalam penyelesaian permasalahan adalah sebagai berikut :

1. Setiap komponen siklus dianalisis sebagai volume atur pada kondisi tunak.

2. Pompa beroperasi secara adiabatik

3. Generator memiliki efisiensi sebesar $98 \%$.

4. Efek energi kinetik dan potensial diabaikan.

\section{B. Efisiensi Thermal Plant}

Berdasarkan data yang diperoleh dari operator control room, diambil data sebanyak 1 bulan pada bulan september 2017 untuk mewakili perhitungan efisiensi thermal PLTP Unit II, dimana data 1 bulan ini telah dirata-rata pada spread sheet Excel. Dalam perhitungan parameter yang digunakan (tekanan, temperatur, laju aliran, daya generator) diambil nilai rata - rata perhari selama 24 jam. Pengolahan data hasil perhitungan menggunakan software Microsoft Excel 2016. Berikut gambar sistem pembangkit listrik tenaga panas bumi:

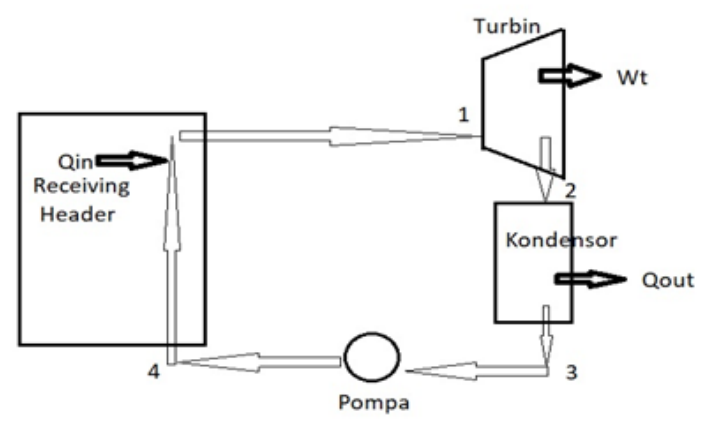

Gambar 1. Sistem Pembangkit Listrik Tenaga Panas Bumi[4]

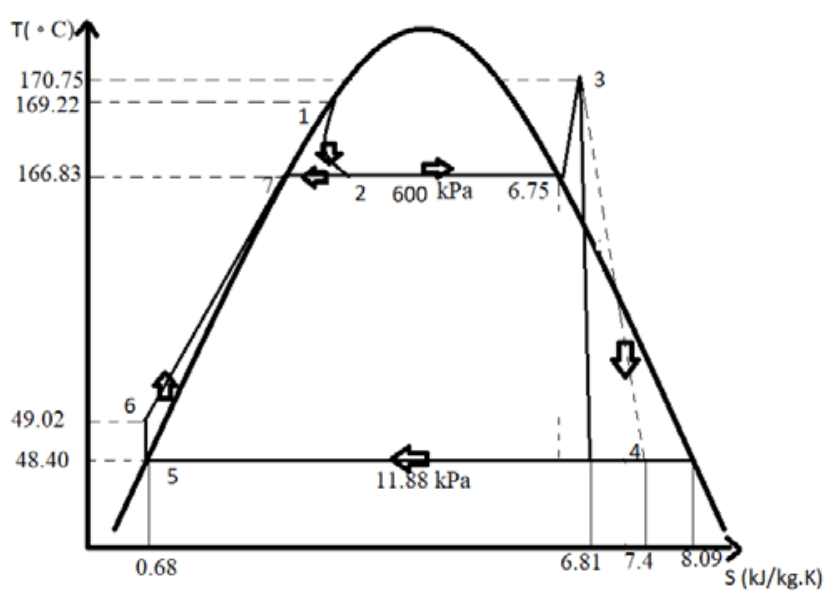

Gambar 2. Diagram T-s Siklus Single Flash pada PLTP Kamojang Unit II

Sehingga, setelah menghitung dengan tahapan-tahapan Perhitungan Efisiensi Thermal Plant didapatkan efisiensi thermal sistem PLTP Kamojang sebagai berikut :

$\eta=\frac{\sum W}{\text { Qin }}=\frac{W_{\text {turbin }}-W_{\text {pompa }}}{h 3-h 6}$

$\eta$ sistem $=\frac{\left(h_{3}-h_{4}\right)-W_{\text {pompa }}}{2783,53 \frac{\mathrm{kJ}}{\mathrm{kg}}-205,24 \frac{\mathrm{kJ}}{\mathrm{kg}}}$

$\eta$ sistem $=\frac{\left(2783,53 \frac{\mathrm{kJ}}{\mathrm{kg}}-2283,53 \frac{\mathrm{kJ}}{\mathrm{kg}}\right)-(-0,645) \mathrm{kJ} / \mathrm{kg}}{2783,53 \frac{\mathrm{kJ}}{\mathrm{kg}}-205,24 \frac{\mathrm{kJ}}{\mathrm{kg}}}$

$\eta$ sistem $=\frac{500 \frac{\mathrm{kJ}}{\mathrm{kg}}+0,645 \mathrm{~kJ} / \mathrm{kg}}{2578,29 \frac{\mathrm{kJ}}{\mathrm{kg}}}$

nsistem $=19,41 \%$

Pembangkit listrik tenaga panas bumi cenderung memiliki efisiensi termal yang rendah karena fluida panas bumi berada pada temperatur yang lebih rendah dibandingkan dengan uap atau air mendidih. Efisiensi thermal pada PLTP Kamojang Unit II bernilai 19,41\%, maka pernyataan diatas benar adanya bahwa PLTP cenderung memiliki efisiensi thermal yang rendah. Pada hukum termodinamika, rendahnya temperatur akan membatasi efisiensi dari sistem dalam mengambil energi selama menghasilkan listrik. Jadi sisa panas akan terbuang, kecuali jika bisa dimanfaatkan secara langsung, misalnya untuk pemanas ruangan. Efisiensi sistem yang rendah dapat juga disebabkan oleh adanya kerugian-kerugian energi panas yang banyak sekali di temukan pada peralatan atau komponen-komponen pada PLTP. Misalnya turbin uap, pada sudu-sudu dan rumah turbin banyak kehilangan panas karena proses ekspansi uap air. Adapun, kebocoran uap juga dapat menimbulkan kerugian-kerugian yang akhirnya 
menyebabkan efisiensi menjadi turun. Peralatan lain seperti kondensor juga dapat mempengaruhi efisiensi sistem yaitu perubahan tekanan. Jika kondensor memiliki tekanan vakum rendah maka kinerja dan efisiensi dari turbin akan meningkat, dan apabila tekanan vakum bernilai tinggi maka kinerja dan efisiensi dari turbin akan menurun. Jika dilihat pada Gambar 2, yaitu diagram T-s, penyimpangan siklus aktual dari siklus ideal dikarenakan beberapa faktor seperti gesekan fluida, kerugian panas dan kebocoran uap. Gesekan fluida mengakibatkan tekanan jatuh pada banyak peralatan seperti steam receiving header, kondensor dan di pipa-pipa yang menghubungkan banyak peralatan. Dengan demikian sangat diperlukan dalam menjaga kinerja setiap komponen atau peralatan PLTP agar tetap optimal sehingga PLTP memiliki efisiensi yang baik. Selain komponen atau peralatan yang dapat mempengaruhi efisiensi sistem adalah uap yang keluar dari sumur produksi, karena uap yang keluar dari sumur produksi mengandung berbagai macam unsur kimia yang dapat merusak sudu-sudu turbin sehingga akan berpengaruh pada efisiensi PLTP.

\section{Eksergi}

1) Tinjauan Plant

Pengambilan data dan tinjauan plant dari penelitian analisa thermal ini dilakukan di PT. Indonesia Power UPJP Kamojang. Dalam peninjauan plant, berdasarkan Piping Instrument Diagram (P\&Id) yang didapatkan dari PT. Indonesia Power UPJP Kamojang yang dapat di sederhanakan menjadi Proses Flow Diagram (PFD) maka jenis PLTP yang berada di PT. Indonesia Power UPJP Kamojang adalah jenis single-flash power plant. Kemudian dilakukan penentuan state untuk menghitung nilai eksergi. Dalam menghitung nilai eksergi setiap statenya digunakan data temperature, tekanan dan laju aliran pada setiap state. Berikut gambar state pada PT. Indonesia Power UPJP Kamojang :

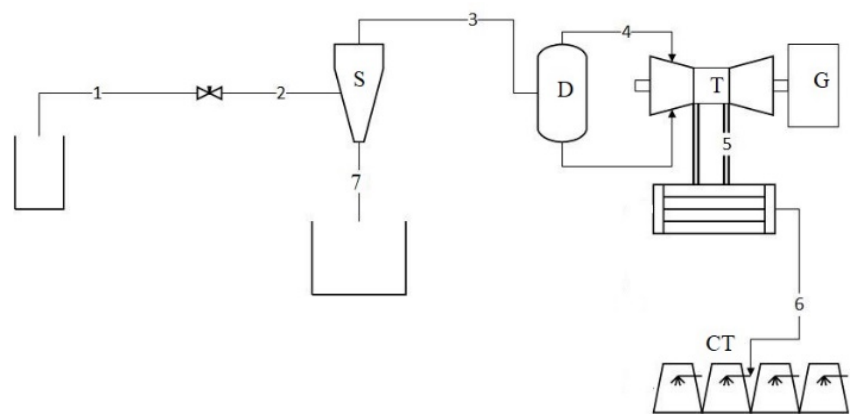

Gambar 3. State pada PT. Indonesia Power UPJP Kamojang

\section{2) Perhitungan Eksergi pada Plant}

Setelah Proses Flow Diagram (PFD) diberikan state, kemudian dilakukan perhitungan eksergi. Sebelum melakukan perhitungan eksergi, berikut data yang diperoleh dari PT. Indonesia Power UPJP Kamojang pada bulan September 2017. Data tersebut digunakan untuk perhitungan eksergi sesuai dengan state yang diberikan seperti pada Gambar 3.

Tabel 1.

Data untuk Perhitungan Eksergi

\begin{tabular}{cccc}
\hline \hline State ke- & T ( $\mathbf{C})$ & $\mathbf{P}$ (bar) & m $\mathbf{~ k g / s )}$ \\
\hline 0 & 17 & - & 113,117 \\
1 & 169,22 & 6,5 & 113,117 \\
2 & 166,83 & 6,5 & 113,117 \\
3 & 166,83 & 6,0 & 110,51 \\
4 & 170,75 & 6,0 & 110,51
\end{tabular}

Tabel 2.

Hasil Perhitungan Eksergi dari State

\begin{tabular}{cc}
\hline \hline State ke- & $\mathbf{E}_{\mathbf{k}} \mathbf{( k W )}$ \\
\hline 0 & 13657,74 \\
1 & 115787,12 \\
2 & 115180,25 \\
3 & 112418,50 \\
4 & 55240,63 \\
5 & 21911,92 \\
6 & 21701,95 \\
7 & 2324,50 \\
\hline
\end{tabular}

Setelah diperoleh hasil perhitungan eksergi pada Tabel 2, maka dapat diperoleh eksergi loss dan efisiensi eksergi dengan persamaan 12 dan persamaan 13, berikut perhitungan eksergi loss dan efisiensi eksergi setiap unit :

Tabel 3.

Nilai dari Eksergi Loss dan Efisiensi Eksergi dari Setiap Unit

\begin{tabular}{lcc}
\hline \hline Keterangan & Eksergi Loss (kW) & Efisiensi Eksergi (\%) \\
\hline Separator & 606,87 & $99,47 \%$ \\
Demister & 2761,75 & $97,60 \%$ \\
Turbin & 7177,87 & $52,50 \%$ \\
Kondensor & 7131,26 & $87,09 \%$ \\
Cooling Tower & 209,97 & $99,04 \%$ \\
\hline \hline
\end{tabular}

Selanjutnya, dapat dihitung efisiensi eksergi overall. Dengan menggunakan persamaan 14 maka di dapatkan efisiensi eksergi overall sebagai berikut :

$$
\begin{aligned}
\eta_{I I} & =\frac{W_{\text {net }}}{E_{\text {in }}} \\
\eta_{I I} & =\frac{52904,45 \mathrm{~kW}}{112418,50 \mathrm{~kW}} \\
& =47,06 \%
\end{aligned}
$$

Pada Tabel 3, dapat dilihat eksergi loss pada separator dan demister yaitu sebesar 606,87 kW dan 2761,75 kW, untuk efisiensi eksergi dari separator dan demister yaitu sebesar 99,47 \% dan 97,60 \%. Nilai efisiensi eksergi pada separator dan demister dapat dikatakan cukup tinggi karena hampir mendekati $100 \%$. Eksergi loss pada separator dan demister dapat disebabkan karena beberapa hal yaitu seperti terbentuknya korosi akibat kotoran yang ada di dalam dust collector meskipun telah di drain secara berkala baik otomatis ataupun manual. Selain itu kerusakan sambungan akan menyebabkan kehilangan panas didalam separator. Sedangkan pada demister, jika uap yang dihasilkan oleh demister tidak benar-benar kering dan kotor maka akan menyebabkan vibrasi, erosi dan pembentukan kerak pada turbin sehingga dapat menimbulkan losses. Untuk turbin dan kondensor dapat dilihat bahwa 2 komponen tersebut memiliki eksergi loss yang cukup tinggi tetapi nilai efisiensi ekserginya 
lebih kecil dibandingkan komponen separator dan demister, yaitu untuk turbin nilai eksergi lossnya adalah 7177,87 kW dan untuk kondensor nilai eksergi lossnya adalah 7131,26 kW. Eksergi loss yang terjadi pada turbin dapat terjadi akibat pengaruh dari uap demister yang tidak benar-benar kering atau kotor, sehingga menyebabkan terbentuknya kerak pada sudu-sudu turbin. Sedangkan pada kondensor, eksergi loss yang terjadi adalah akibat dari adanya hambatan saat pelepasan kalor karena kotoran-kotoran dalam pipa kondensor. Selain itu pengaruh dari level air kondensat akan mempengaruhi kinerja dari kondensor, karena jika level air kondensat terlalu tinggi maka akan menyebabkan kondensor pada bagian bawah tergenang dan mengurangi luas permukaan pendingin karena uap tidak dapat menyentuh bagian tube yang tergenang tersebut, dan pada akhirnya temperatur dan tekanan kondensasi akan menjadi naik. Adapun komponen pada kondensor yang sangat penting bagi kinerja kondensor yaitu pompa vakum kondensor yang berfungsi sebagai menghisap gas-gas yang tidak dapat terkondensasi. Eksergi loss pada cooling tower sebesar 209,97 kW dengan efisiensi eksergi sebesar 99,04\%. Untuk meningkatkan kinerja cooling tower yang perlu diperhatikan adalah perawatan dan pembersihan tower. Selain itu, yang mempengaruhi adalah saat proses pelepasan panas, pada proses pelepasan panas alat yang digunakan di dalam cooling tower adalah kipas atau fan sehingga perlu diperhatikan agar kerja fan tidak terlalu berat. Jika melihat Tabel 3, dapat disimpulkan bahwa semakin tinggi eksergi loss pada suatu komponen, maka efisiensi ekserginya semakin rendah, dan jika eksergi lossnya rendah maka efisiensinya semakin tinggi. Apabila nilai efisiensi semakin tinggi, maka sistem tersebut dapat dikatakan baik, karena energi yang dibutuhkan untuk memulai kerja pada sistem secara keseluruhan lebih kecil dari pada energi yang dihasilkan.

\section{Termoekonomi}

Dalam menghitung biaya rugi eksergi, menggunakan acuan Tarif Dasar Listrik Indonesia per kWh bulan Maret 2018. Untuk menentukan biaya rugi eksergi per unit dapat dilakukan dengan perhitungan termoekonomi menggunakan persamaan 11. Asumsi yang digunakan pada Tarif Dasar Listrik Indonesia bulan Maret 2018 untuk industri yang tidak mendapatkan subsidi sebesar Rp 1.467,28 per kWh yang termasuk pada golongan I-4/TT dengan batas daya lebih dari $30.000 \mathrm{kVa}$. Sehingga hasil perhitungannya sebagai berikut :

Tabel 4.

Hasil Perhitungan Biaya Rugi Eksergi per Komponen

\begin{tabular}{llll}
\hline \hline Keterangan & $\mathbf{E}_{\text {kloss }}(\mathbf{k W})$ & Cost (Rp/bln) \\
\hline Separator & 606,87 & $21.370 .757,1$ \\
Demister & 2761,75 & 97.254 .253 \\
Turbin & 7177,87 & $252.766 .682,24$ \\
Kondensor & 7131,26 & $251.125 .324,1$ \\
Cooling Tower & 209,97 & $7.394 .034,76$ \\
\hline \hline
\end{tabular}

Dari hasil perhitungan pada Tabel 4 dapat dilihat biaya rugi eksergi pada komponen separator dan demister sebesar 21.370.757,1 Rp/bln dan 97.254.253 Rp/bln. Biaya rugi eksergi yang paling tinggi adalah turbin yaitu sebesar 252.766.682,24 Rp/bln. Sedangkan biaya rugi untuk komponen kondensor adalah sebesar 251.125.324,1 Rp/bln. Pada Tabel 4, eksergi loss terbesar juga terdapat pada komponen turbin, sedangkan eksergi loss terendah terdapat pada komponen cooling tower sehingga biaya rugi eksergi pada cooling tower bernilai kecil sebesar 7.394.034,76 Rp/bln. Sehingga dapat disimpulkan bahwa biaya rugi eksergi akan berbanding lurus dengan eksergi lossnya. Beberapa faktor yang dapat mempengaruhi besarnya nilai eksergi dan biaya rugi eksergi, salah satunya adalah besarnya masukan serta keluaran proses yang dapat berimbas pada efisiensi dan besar biaya rugi eksergi komponen tersebut. Semakin besar nilai eksergi lossnya atau rugi eksergi yang hilang, maka biaya yang dibutuhkan juga semakin banyak.

\section{KESIMPULAN DAN SARAN}

\section{A. Kesimpulan}

Efisiensi thermal sistem pembangkit listrik tenaga panas bumi PT. Indonesia Power UPJP Kamojang sebesar 19,41\%. Pada hukum termodinamika, rendahnya temperatur akan membatasi efisiensi dari sistem dalam mengambil energi selama menghasilkan listrik. Jadi sisa panas akan terbuang, kecuali jika bisa dimanfaatkan secara langsung, misalnya untuk pemanas ruangan. Efisiensi sistem yang rendah dapat juga disebabkan oleh adanya kerugian-kerugian energi panas yang banyak sekali di temukan pada peralatan atau komponen-komponen pada PLTP.

Dilihat dari hasil perhitungan untuk efisiensi eksergi sistem sebesar 47,06\%. Sedangkan hasil perhitungan efisiensi eksergi pada tiap-tiap komponen dengan efisiensi eksergi terbesar terdapat pada komponen separator yaitu 99,47\%. Semakin tinggi eksergi loss pada suatu komponen, maka efisiensi ekserginya semakin rendah, dan jika eksergi lossnya rendah maka efisiensinya semakin tinggi.

Biaya rugi eksergi terbesar berdasarkan termoekonomi adalah pada komponen turbin yaitu sebesar 1.995.895.322 Rp/bln, karena eksergi loss pada turbin dikatakan cukup tinggi sebesar 7177,87 kW. Sedangkan eksergi loss terendah terdapat pada komponen cooling tower sehingga biaya rugi eksergi pada cooling tower bernilai kecil sebesar 7.394.034,76 Rp/bln. Berbeda dengan perbandingan antara eksergi loss dengan efisiensi eksergi, semakin besar eksergi lossnya maka efisiensi eksergi pada komponen tersebut bernilai kecil. Biaya rugi eksergi berbanding lurus dengan eksergi loss dari setiap komponen.

\section{B. Saran}

Adapun saran dari penulis untuk pembangkit listrik yang telah diteliti yaitu perlu dilakukannya maintenance secara rutin terhadap komponen turbin serta kondensor dikarenakan memiliki eksergi loss yang cukup tinggi yang akan mempengaruhi efisiensi dari sistem.

\section{DAFTAR PUSTAKA}

[1] I. S. Budipertiwi, "Analisa termoekonomi pada sistem kombinasi turbin gas - uap PLTGU PT PJB Unit Pembangkitan Gresik,” Institut Teknologi Sepuluh Nopember, 2012.

[2] P. Suharmanto, A. N. Fitria, and S. Ghaliyah, "Indonesian geothermal energy potential as source of aternative energy power plant,” $\mathrm{KnE}$ Energy, vol. 1, no. 1, p. 119, Nov. 2015

[3] J. Junaldi, "Prediksi Daya Listrik Geothermal Power Plant,” Institut Teknologi Sepuluh Nopember, 2012.

[4] M. J. Moran and H. N. Shapiro, Fundamentals of engineering thermodynamics, 5th ed., SI version. Chichester: John Wiley \& Sons, 2006.

[5] E. R. D. Balqis, "Optimasi daya listrik pada PT Pertamina Geothermal Energy Area Kamojang, Jawa Barat,” Institut Teknologi Sepuluh Nopember, 2012.

[6] N. O. Wijaya, G. Nugroho, and S. Sarwono, "Analisa Eksergi Dan Termoekonomi Pada Plant Penstabilan Kondensat,” Institut Teknologi Sepuluh Nopember, 2012. 